\title{
LA MUJER... ¿CLASE SOCIAL? ALGUNOS ANTECEDENTES HISTORICOS
}

\author{
Judith Astelarra
}

Uno de los debates teóricos actuales más importantes en el movimiento feminista español se centra en torno a la pregunta sobre si la mujer constituye o no una clase social. El artículo aporta el análisis de varios ejemplos históricos al debate. Se estudia la participación de las mujeres en la Revolución Francesa, las luchas obreras europeas del siglo xIx, el sufragismo y el gobierno de la Unidad Popular chileno. Se señala cómo en todos estos casos se han desarrollado dos líneas distintas y a veces contradictorias de movilización femenina. Esto se ha reflejado en el siglo XIx en la existencia de dos tipos de feminismo: el feminismo burgués y el feminismo proletario. Si bien ambos coinciden en señalar la inferioridad de la mujer, tienen significativas diferencias respecto a las dimensio nes de esta opresión y al enjuiciamiento de la sociedad capitalista. 


\section{Introducción}

Dentro del contexto de avance del movimiento feminista en España se ha producido un intenso debate entre dos corrientes: la que define a la mujer como una clase social y aquella que se opone a esta conceptualización, señalando que si bien todas las mujeres sufren un problema de marginación y desigualdad, la diferencia de clases de la sociedad capitalista también se refleja en las mujeres. Esta polémica teórica no es nueva, se remonta, aunque en otros términos, al siglo Xrx. El renacer del movimiento feminista a partir de los años sesenta y el mayor grado de conceptualización teórica sobre la opresión de la mujer, si se lo compara con movimientos anteriores, ha replanteado esta polémica. De hecho, ya no se puede situar el problema en dos versiones extremas, pues hay diversas concepciones que de alguna manera intentan matizar una u otra posición. Sin embargo, a pesar de los matices, en su aspecto esencial se mantiene esta disparidad de criterios. Es decir, siguen existiendo dos versiones opuestas sobre cómo calificar a las mujeres, en su conjunto.

El enfrentamiento entre ambas concepciones sobre la opresión de la mujer tiene consecuencias a la hora de intentar construir una teoría feminista y también, evidentemente, al plantear un movimiento feminista y un programa de acción. Si bien en determinados momentos los diversos grupos feministas de un país ( $\mathrm{y}$ esto también se evidencia al estudiar la historia del feminismo) pueden coincidir en una movilización conjunta de todas las mujeres, hay otras situaciones en que las mujeres se han dividido en grupos opuestos entre sí.

Por ello no es suficiente una discusión teótica sobre las dimensiones de la opresión de la mujer para clarificar la validez de estas teorías. También es importante combinar este análisis con datos históricos que permitan contrastar estas corrientes teóricas con la realidad. El obstáculo principal es la escasez de registros históricos sobre las luchas de las mujeres. Afortunadamente, recientes estudios nos permiten tener nuevos datos que ilustran sobre algunos de estos problemas. 
El propósito de este artículo es el uso de los antecedentes históricos más significativos para clarificar aspectos de la discusión teórica. Serán analizadas situaciones históricas concretas en las que se han producido movilizaciones importantes, ya sea en demanda de reivindicaciones sociales generales o específicamente feministas. La intención del análisis incluye por un lado el desarrollo tanto ideológico como práctico del feminismo, es decir, cuáles han sido las ideologías feministas que se desarrollaron, las metas y los programas de los distintos movimientos feministas y la base social de las mujeres que los sustentaron. Por otro lado, interesa conocer la relación entre estos movimientos feministas y los movimientos políticos generales, en especial el desarrollo del movimiento obrero. También es importante saber quiénes fueron las mujeres que participaron en estos movimientos sociales y las que se opusieron a ellos. Por último, cuál ha sido la respuesta del movimiento obrero a las reivindicaciones y a la organización de la mujer. En definitiva, interesa conocer las coincidencias y divergencias de los distintos grupos sociales de mujeres entre sí y las de éstas con el movimiento obrero. Con esos elementos se pueden entregar algunas bases para la discusión teórica sobre si la mujer constituye una clase social o no.

Es evidente que este artículo no puede ser exhaustivo. En la medida que se completen estudios históricos y se pueda evaluar desde una perspectiva más amplia esta nueva práctica feminista, la situación será más clara. El material histórico usado corresponde a estudios recientemente publicados. ${ }^{1}$ Los casos históricos analizados son: la Revolución Francesa; el desarrollo de las luchas obreras del siglo xIx; el sufragismo, especialmente en los Estados Unidos, y finalmente un caso reciente, el del gobierno de la Unidad Popular en Chile.

\section{Los elementos teóricos de la discusión}

La corriente denominada feminismo radical, cuyo principal exponente ha sido Shulamith Firestone, sostiene la posición de que la mujer constituye

1. Los datos históticos que se utilizan en el artículo han sido tomados de los siguientes estudios: Paule Marie Duhet, Las mujeres y la revolución (1789-1794) (Barcelona: Ediciones Península, 1974); Maïte Albistur y Daniel Armogathe, Histoire du Feminisme Français (París: Éditions des Femmes, 1977); Sheila Rowbotham, Women, Resisiance and Revolution (Nueva York: Vintage Books Edition, 1974); Judith Hole y Ellen Levine, «The First Feminists», en Jo Freeman, Women: a Feminist Perspective (California: Mayfield Publishing Co., 1975); y Karen Sacks, «Class Roots of Feminism, New Left Review, $29-9$ (febrero 1976). 
una clase social. Para Firestone el análisis de Marx y Engels tiene el gran mérito de haber desarrollado un método de análisis histórico, a la vez dialéctico y materialista, superior a cualquier otro intento de explicación histórica. Se equivocaron, en cambio, al intentar desarrollar este análisis sobre la base de variables económicas, ya que el verdadero motor de la historia fue la división originada en el sexo. Es así como, parafraseando a Engels, pero modificándolo, sostiene a modo de resumen que:

El materialismo histórico es aquella concepción del curso histórico que busca la causa última y la gran fuerza motriz de los acontecimientos en la dialéctica del sexo: en la división de la sociedad en dos clases biológicas diferenciadas con fines reproductivos y en los conflictos de dichas clases entre sí; en las variaciones habidas en los sistemas de matrimonio, reproducción y educación de los hijos creadas por dichos conflictos; en el desarrollo combinado de otras clases físicamente diferenciadas (castas); y en la prístina división del trabajo basada en el sexo y que evolucionó hacia un sistema (económico-cultural) de clases. ${ }^{2}$

De esto se deduce que las contradicciones principales dentro de la sociedad se producen entre hombres y mujeres, no entre la burguesía y el proletariado. La mujer constituye una clase social cuya tarea es la modificación total de las sociedades. Es, por lo tanto, la llamada a hacer la revolución final y la constitución de una sociedad sin desigualdades.

En el extremo opuesto de esa interpretación sobre la opresión de la mujer se sitúa la que podemos denominar la concepción marxista ortodoxa. Señala que la situación de inferioridad de la mujer apareció con el surgimiento de la propiedad privada. La opresión de la mujer sería así un subproducto de la explotación capitalista, que será resuelta cuando el proletariado haga la revolución. Lo que importa entonces es la lucha de clases y no otras luchas. Si bien Engels señaló que en términos de la relación hombre-mujer ésta podía ser comparada con el proletariado y al hombre con la burguesía, también es cierto que en los textos clásicos marxistas, aunque profundamente preocupados del problema de la mujer, no existe una teorización consistente sobre el origen de la problemática. Cuando aparece, corresponde al tipo de análisis idealista o moralista de los socialistas utópicos que Marx y Engels habían criticado tan sistemáticamente. Pero, al menos, tanto en la discusión como en la práctica de los primeros

2. Shulamith Firestone, La dialéctica del sexo (Barcelona: Kairós, 1976), p. 22. 
comunistas existe un claro interés por el tema. Este análisis incipiente se transformó, merced al stalinismo, en una concepción que redujo el problema de la mujer a una cuestión secundaria, que sería resuelta una vez que el proletariado consolidara su revolución, que lograra la abolición de la propiedad privada e instaurara una sociedad socialista. Con esos antecedentes el marxismo ortodoxo ha combatido históricamente la organización autónoma de las mujeres considerándola un fenómeno burgués, atacando, incluso, débiles intentos de organización de mujeres socialistas. Esta forma de pensamiento persiste en nuestros días, tanto en organizaciones consideradas ortodoxas (por ejemplo, el Partido Comunista Francés) como en organizaciones de la llamada extrema izquierda. ${ }^{3}$

Entre estas dos concepciones extremas surgen distintas corrientes intermedias. La más importante es la que, emergiendo de la tradición marxista, sostiene el hecho de que si bien las mujeres no forman una clase social, también es cierto que la mujer tiene una problemática específica que no ha sido ni podrá ser resuelta por el proletariado. En este sentido señala que el marxismo ha sido débil tanto teórica como prácticamente para resolver la opresión de la mujer. Teóricamente porque ha sido incapaz de estructurar un análisis completo sobre sus mecanismos históricos. Prácticamente porque también el proletariado es machista. Por lo cual las revoluciones socialistas no han resuelto la situación de inferioridad de la mujer (si bien se pueden notar progresos bastante importantes). Este grupo da origen a la corriente que se ha llamado de modo general feminismo socialista, que cree que simultáneamente se debe luchar por la transformación del sistema capitalista y el sistema patriarcal.

3. Fini Rubio, en «Introducción y estudio previo», varios autores, Marxismo y liberación de la mujer (Madrid: Dédalo Ediciones, 1977), p. 18, recoge el siguiente párrafo de un documento del Partido del Trabajo de Cataluña:

«Estos movimientos burgueses llamados Women's lib tienen como objetivo la igualdad de derechos con el hombre en abstracto, desligados totalmente del proceso de lucha de clase. "Su enemigo" es el hombre y luchan contra él para arrebatarle su supremacía en todos los campos. Estos movimientos han fracasado y siempre seguirán fracasando. Es ésta una lucha racista de las mujeres contra los hombres, o sea, contra la mitad de la humanidad, que se ha apoderado de los instrumentos de poder y fuerza y explota a la otra mitad. Practican [estas mujeres] abiertamente el odio de clases sexuales. El odio o el miedo al hombre les lleva a tomar posiciones tan radicales que la mayoría de ellas son lesbianas (sic). A la vez que radicalizan su postura desvían el objetivo de la lucha creando confusión al fijar como enemigo al sexo masculino, lo cual produce enfrentamientos en el seno de la misma clase beneficiando así a la clase explotadora.» 
Juliet Mitchell ${ }^{4}$ señala que las dos primeras concepciones presentan sus posiciones como opuestos polares. Caracteriza a una como empiricista y a la otra como idealista. El feminismo radical trata de hacer una teoría sobre la experiencia concreta de la opresión. $\mathrm{El}$ marxismo ortodoxo abs. tracto no enfrenta realmente el problema de la opresión específica de las mujeres, idealizando su rol de oprimidas. Pero si lo que intenta hacer el socialismo es una revolución total, los grupos oprimidos deben tomar conciencia de su opresión y luchar para que ésta sea suprimida. Por lo tanto, una revolución de este carácter no puede basarse exclusivamente en el proletariado, sino que debe también incorporar las demandas de todos los otros grupos oprimidos: las mujeres, los grupos raciales, los marginados sexuales, etcétera. Según Mitchell, la debilidad en el problema de los países socialistas para resolver la opresión de la mujer, proviene del hecho que las mujeres, que participaron en el movimiento general, no se organizaron específicamente en torno a su propia problemática.

Ahora bien, cuando las mujeres señalan que todas por igual son oprimidas y se plantean movimientos de lucha y liberación, ¿proponen todas el mismo tipo de sociedad futura? ¿Se siente la mujer burguesa, que lucha por su igualdad con el hombre, solidaria con los otros grupos oprimidos? ¿Lo ha expresado así históricamente? ¿Está dispuesta a luchar por la transformación de la sociedad capitalista?

Éstas son algunas de las preguntas que se plantean a continuación.

\section{La Revolución Francesa}

Antes de la Revolución Francesa ya habían existido movimientos de mujeres pidiendo igualdad con el hombre. En las cortes europeas las mujeres ilustradas pedian igualdad educativa. Al iniciarse el protestantismo, hubo un movimiento de mujeres inglesas que exigían su derecho a ser predicadoras, ya que hombre y mujer eran iguales ante Dios. Así, pequeños grupos de mujeres se plantearon ya su problema de opresión. Sin embargo, no dejaban de ser grupos de élite pidiendo derechos iguales para una minoría de mujeres. Es en la Revolución Francesa en que coinciden por primera vez esta tradición elitista con un amplio movimiento de masas. Por primera vez grupos de mujeres ilustradas se encuentran en la acción, con grandes masas de mujeres que participaban en la Revolución Francesa.

La nueva filosofía de la época que precede a la Revolución Francesa y en la cual Rousseau tuvo una gran influencia, se planteó también el

4. Juliet Mitchel Woman's Estate (Nueva York: Vintage Books Edition, 1973). 
problema de los derechos de la mujer. Es así como en estos círculos intelectuales se hablaba de la necesidad de que la mujer tuviera los mismos derechos educativos y políticos que los hornbres. Sobre todo se hacía especial hincapié en la necesidad de que las mujeres recibieran educación, sin la cual no podrían integrarse plenamente en la sociedad. Aparecieron así gran cantidad de libros y artículos que solicitaban esta igualdad. Una tal Madame B., que se mantuvo en el anonimato, afirmó en un libro: «Sempiternos objetos de la admiración y del desprecio varonil, las rnujeres en medio de esta agitación general, ¿no podrían también ellas hacer oír su voz?» ${ }^{5}$

$\mathrm{Y}$ las mujeres hicieron oír su voz. Coincidiendo con estos movimientos en los círculos intelectuales, gran cantidad de mujeres del tercer estado y del pueblo comenzaron a reclamar reivindicaciones. Las mujeres del pueblo pidieron pan, trabajo y especialmente reivindicaciones económicas para ellas y para sus compañeros. Fueron estas mujeres las que estuvieron a la cabeza de la toma de la Bastilla y las que participaron en forma activa en las guerras que debió enfrentar la joven República Francesa a partir de 1791.

Hay, así, dos grupos de mujeres socialmente diferenciados. Las mujeres de élite provenientes de los círculos intelectuales y en algunos casos de la aristocracia francesa que estaban al lado de la burguesía y las mujeres del pueblo. Ambos grupos coincidieron en la demanda de iguales derechos para mujeres y hombres. Sin embargo, sus demandas específicas, su ideología política y su participación en la Revolución Francesa fueron distintas. La influencia de uno u otro grupo en el proceso revolucionario cambió según el paso del tiempo. Se pueden distinguir tres etapas claramente diferenciadas: la primera desde 1789 (toma de la Bastilla) hasta 1791; la segunda desde 1791 hasta 1793 y la tercera a partir de 1793.

La primera etapa se caracterizó por el predominio de mujeres provenientes de grupos intelectuales y elitistas. Olympe de Gouges, Theroigne de Mericourt y Etta Palm son sus principales exponentes. Su acción se caracterizó por su presencia en la asamblea nacional, en los salones donde se encontraban los nuevos dirigentes y en los lugares de reunión de las nuevas élites políticas. Reclamaban, sobre todo, el derecho de la mujer a la igualdad educativa y a la igualdad política, es decir, su derecho a ser ciudadanas en igualdad de condiciones que los hombres. Políticamente estas mujeres eran moderadas políticas, llegando alguna de ellas a apoyar la existencia de una monarquía no absolutista.

Entre 1791 y 1793 el proceso general se radicalizó: es la época de los jacobinos y su enfrentamiento con los girondinos. La época en que los

5. Duhet, op. cit., (1974), p. 30. 
nuevos dirigentes debieron recurrir a amplias movilizaciones populares para hacer frente a la agresión externa que intentó poner fin a la Revolución Francesa. Las mujeres se organizaron en clubs femeninos. Clubs que esta vez estaban dirigidos por mujeres provenientes del movimiento popular, como por ejemplo Claude Lacombe. Participaron en forma activa en todos los frentes, trabajaton en la producción dentro del país, algunas se incorporaron al ejército, otras lo hicieron en hospitales, antes a cargo de las monjas, que los abandonaron, y otras, por último, se hicieron responsables de controlar la sedición interna. Esta sedición se manifestaba sobre todo en el acaparamiento de productos, en el mercado negro y en la inflación. Al mismo tiempo trabajaron con los sectores políticos más radicales que exigieron que la Revolución Francesa no traicionase sus ideales y no se aliase con sectores provenientes del Antiguo Régimen.

A partir de 1793 y una vez que Robespierre tomó el poder, llegó el momento de detener el radicalismo de la Revolución. El ataque comenzó por las mujeres. El club más importante, el de las republicanas revolucionarias, fue disuelto. Sus dirigentes, encarceladas. $Y$ lo que es más importante, se niega a la mujer, en la Constitución, el derecho político de ser ciudadana. Las mujeres no eran necesarias. Su organización asustaba, por lo tanto deben ser destruidas. Los grupos políticos radicales, antes sus aliados, también se enfrentaron con ellas, acusándolas de contrarrevolucionarias por intentar desorganizar la sociedad francesa. La revolución exigió a sus mujeres que volvieran a asumir lo que es su rol proveniente de la naturaleza, es decir, de esposas y madres. Si bien las mujeres habían tenido una profunda diferencia en cuanto a sus objetivos y su acción política, finalmente ambos grupos son destruidos. En la destrucción del movimiento feminista colaboraron por igual los hombres de la burguesía, que creían que había llegado el momento de congelar el proceso revolucionario francés, y los sans culottes. Las ilusiones de libertad e igualdad de las mujeres llegaron a su fin. La mujer volvió a partir de ese momento a la situación tradicional prerrevolucionaria. No consiguió, en verdad, ninguna de sus reivindicaciones. $\mathrm{Ni}$ igualdad política, ni igualdad educativa, ni mucho menos posibilidad de participación económica.

Sin embargo, la Revolución Francesa desencadenó una serie de acontecimientos sobre los que ya no se puede dar marcha atrás. Las mujeres habían podido desarrollar un movimiento en demanda de derechos iguales. El fracaso no las hizo volver atrás y durante todo el siglo xIx volvieron a aparecer nuevos intentos de reconquistar los derechos perdidos y aquellos otros que no fueron nunca alcanzados. El feminismo se convirtió así en un movimiento, dejó de ser el proceso de una pequeña élite de mujeres. Pero la Revolución Francesa también evidenció la diferencia que existe entre 
las propias mujeres. Es a partir de aquí que comienzan a demarcarse las dos líneas del feminismo que más tarde, en el transcurrir del siglo XIX, serían caracterizadas como el feminismo burgués y el feminismo proletario. Dos corrientes feministas con dos desarrollos ideológicos paralelos y con dos tipos de práctica distinta. En algunos casos ambas líneas confluirían, pero en otros se harían antagónicas entre sí.

\section{Desarrollo ideológico durante el siglo XIX}

La diferencia entre ambos feminismos se puede constatar tanto a nivel ideológico como a nivel de práctica. En los comienzos del siglo xxx predominó el feminismo burgués, que comenzó su desarrollo ideológico. Se trataba de elaboraciones que hacían los grupos de vanguardia de las mujeres que participaron en la Revolución Francesa o reflejaban en sus ideas las lecciones allí aprendidas. El feminismo proletario, en cambio, se expresa sin ideología en la acción de las mujeres en la calle. Acción que se caracteriza, fundamentalmente, por las demandas de pan, es decir, demandas económicas muy inmediatas. En la segunda mitad del siglo XIX, en cambio, tanto a nivel ideológico como a nivel práctico, ambas corrientes comenzaron a diferenciarse. Hacia fines del siglo XIx y como consecuencia del movimiento sufragista, las mujeres comenzaron a plantearse la militancia en una u otra línea y, en algunos casos, esta militancia las convirtió en grupos antagónicos.

La obra más importante del incipiente feminismo burgués es Vindicación de los derechos de la mujer, de Mary Wollstonecraft, que es una síntesis de las ideas sobre la liberación de la mujer, producto de la Revo lución Francesa. No sólo pide para las mujeres educación y derechos politicos, sino que plantea el problema de la necesidad de un movimiento feminista para lograrlo. Al mismo tiempo, analiza los mecanismos psicológicos por los cuales las mujeres asumen no sólo una posición de inferioridad en la sociedad, sino que no combaten contra ella. Sin embargo, sus proposiciones no plantean la transformación completa de la sociedad, ni el modo de resolver las injusticias y la opresión de otros grupos sociales que ya era manifiesta en el desarrollo inicial del capitalismo. Es esto lo que diferencia este tipo de pensamiento, del desarrollo ideológico del feminismo proletario.

Durante la primera mitad del siglo xIx aparecieron los primeros escritos de los pensadores socialistas utópicos. Desde un punto de vista moral critican las desigualdades sociales que caracterizan a las sociedades capitalistas. Todos ellos incluyen en sus escritos el problema de la subordina- 
ción de la mujer, planteando algunos mecanismos para resolverla. Sin embargo, sus propuestas no parten de un análisis sistemático sobre los orígenes de estas desigualdades y sobre los mecanismos para transformar la sociedad capitalista. Esto es especialmente extensible en el caso del análisis sobre la opresión de la mujer.

A raíz de estas ideas socialistas la conexión entre pensamiento feminista y socialista se realiza por primera vez. No sólo un sector de mujeres comienza a relacionar su emancipación con la de otros sectores sociales: también la vive en la práctica, a través de su importante participación en los primeros sindicatos y movimientos obreros europeos. En los Estados Unidos la participación de la mujer se expresa tanto en el movimiento sindical naciente como en el que lucha contra la esclavitud. Flora Tristán, en su actividad política y en sus escritos, refleja esta relación entre el movimiento obrero y el movimiento de mujeres.

Es a partir de los escritos de Marx y Engels que el socialismo adquiere base científica. Es decir, que las contradicciones y los conflictos en las sociedades capitalistas no se analizan ya desde un punto de vista moral, sino desde un punto de vista real. Esto es, conociendo sus orígenes, los mecanismos a través de los cuales se expresan, y proponiendo formas para, a través de cambios revolucionarios, transformar la sociedad. Tanto Marx como Engels se preocuparon también del problema de la mujer. Pero, el análisis científico aplicado para entender las contradicciones entre la burguesía y el proletariado no se usa para intentar explicar el origen y las formas de opresión de la mujer. Si bien es cierto que Engels, en algunas ocasiones, señaló que la mujer se podría comparar al proletariado y el hombre a la burguesía, esto no pasa de ser un ejemplo que no se puede tomar al pie de la letra. Bebel es quizá quien en forma más exhaustiva intenta desarrollar el problema en momentos en que $\epsilon l$ movimiento socialista se niega a incluir las reivindicaciones de las mujeres. Pero sus escritos no constituyen una teorfa feminista.

$\mathrm{El}$ análisis marxista clásico deja una gran cantidad de problemas sin resolver. Falta una teoría feminista que explique los orígenes de la opresión de la mujer; la manifestación histórica de esta opresión, es decir, las formas en que varía de sociedad en sociedad; las relaciones entre la opresión de la mujer y la opresión de otros grupos sociales y, por lo tanto, las formas de estructurar un movimiento de mujeres que se preocupe de construir una sociedad en que desaparezcan las desigualdades entre hombre y mujer y entre otros grupos sociales. El feminismo proletario que se origina en el marxismo es así muy débil, poco desarrollado ideológicamente.

Contrasta lo anterior con la obra de Mary Wollstonecraft, la más importante del feminismo burgués. Si bien no es una teoría completa sobre 
La opresión de la mujer, se encuentran en ella muchos elementos relacionados con la situación de inferioridad de las mujeres. Analiza los mecanismos psicológicos y los mecanismos sociales. Señala también la necesidad de que sean las propias mujeres quienes luchen por su liberación y la importancia que tiene la organización en un movimiento feminista. E1 análisis, así, tiene una relación directa con la situación experimentada por las mujeres, lo que no es extraño proveniendo de una mujer. Los ideólogos del feminismo proletario, en cambio, fueron en su mayoría hombres.

Sin embargo, entre ambas corrientes ideológicas hay una diferencia. Las feministas burguesas no están especialmente interesadas en analizar la explotación que sufre la clase trabajadora en el capitalismo. Ni siquiera en lo que se refiere a la situación concreta del trabajo de la mujer. Esto se traduce también en la práctica en la falta de solidaridad e incluso en la oposición abierta de muchas de estas feministas con el movimiento obrero. La mujer burguesa tiene una meta clara: sus derechos iguales a los del hombre, sin modificar sustancialmente la sociedad capitalista. La feminista proletaria, en cambio, está principalmente preocupada en transformar la sociedad capitalista en una sociedad socialista. En su solidaridad con la clase trabajadora pone en segundo lugar sus propias reivindicaciones y las supedita al triunfo de la clase obrera.

\section{El teminismo proletario}

Al mismo tiempo en que se producían estas discusiones ideológicas y teóricas, en el siglo xIX se desarrollaron múltiples luhas sociales tanto en Europa como en los Estados Unidos. En todas, las mujeres participaron activamente, ya sea en apoyo de movimientos reivindicativos generales o en apoyo de sus propias demandas. En el caso del feminismo burgués, cuya más notable manifestación fue el movimiento sufragista, existe una fuerte relación entre ideología y movilización. En cambio, en el caso del incipiente feminismo proletario las ideas de los teóricos socialistas sobre la mujer tienen un impacto mucho menor. Sin embargo, igual que sucedió en la Revolución Francesa, la participación de la mujer en las luchas sociales del momento la lleva necesariamente a cuestionarse, aunque sea de modo elemental, su situación de mujer. Contribuyeron a ello los prejuicios y hostilidad de los cuales fue víctima y que provenían de los propios hombres junto a los cuales luchaba.

La participación de la mujer trabajadora se hizo básicamente en torno al desarrollo del movimiento obrero. Como en la Revolución Francesa, el tema principal que sacó a las mujeres a la calle es el de la escasez econó- 
mica. Pedían pan y lucharon en torno al abastecimiento. Sin embargo, en la medida en que los conflictos se agudizaban, la participación de la mujer se hará extensiva a otros sectores, especialmente a las luchas sindicales.

Fue nuevamente en Francia donde la presencia masiva de las mujeres apareció como más importante. Tanto en los sucesos de 1848 como en la Comuna de París de 1871, la participación y movilización de las mujeres fue general en todos los frentes.

Como en los años de la Revolución Francesa, en 1848 proliferaron clubs y diarios en los que las mujeres analizaron su situación y reivindicaron sus derechos. Esta vez, sin embargo, el movimiento estuvo fuertemente relacionado con el movimiento obrero. Las ideas socialistas habían prendido en el feminismo y así feminismo y socialismo aparecen como dos metas inseparables. Simultáneamente las dirigentes obreras comenzaron a organizar en sindicatos a las mujeres trabajadoras. Jeanne Deroin destacó especialmente por su trabajo tanto en el frente ideológico como en el frente sindical. Al mismo tiempo, las mujeres son solidarias con las luchas del movimiento obrero y con las demandas generales de democracia.

Los sucesos de 1848 terminaron nuevamente con la congelación de las demandas de los obreros y de las mujeres. Entre 1848 y 1871 la situación de los trabajadores empeoró. La situación de las mujeres fue especialmente dura. La mayoría trabajaba en industrias textiles y también en trabajos pesados, como los de construcción y en las minas. También las mujeres encontraron resistencia dentro de los propios medios socialistas. Proudhon, por ejemplo, se manifestó abiertamente hostil a la idea de liberación de la mujer: «La mujer no es más que un complemento del hombre.»

Este período se caracterizó en Francia por el renacer del feminismo burgués, que solicitó el derecho político de la mujer. Apareció así el movimiento sufragista. Las mujeres trabajadoras apoyaron estas demandas y ambas corrientes del feminismo coincidieron en esta reivindicación concreta.

La participación de las mujeres en la insurrección de las Comunas no es más que la culminación de las luchas que habían protagonizado durante el siglo XIX en Francia. Igual que en la Revolución Francesa, la mujer participó en todos los ámbitos: en los abastecimientos, en los servicios, en los hospitales, en las fábricas e incluso en el frente militar. Si bien apoyó el movimiento reivindicativo general, también solicitó demandas específicas: igualdad política, igualdad en la educación, transformación de la familia y de los prejuicios masculinos. Sin embargo, encontró en muchos casos, en especial en su trabajo militar, los prejuicios y la oposición de gran parte de sus compañeros que intentaron restringir sus actividades a servicios secundarios. Es en la práctica concreta donde la mujer trabajadora siente en realidad el peso del machismo de la clase obrera. Pero la 
represión y el fracaso en que terminó la Comuna le afecta tanto como al resto de los trabajadores. De igual manera que en 1789 o en 1848, el golpe más fuerte provino de los hombres de la burguesía, quienes desencadenaron su violencia, especialmente, contra las mujeres trabajadoras. Para el hombre de la burguesía la ideología y la práctica coinciden: la mujer es un ser secundario destinada a la familia y su rol no puede salir de allí. No debe tener por lo tanto ningún derecho.

Hacia finales del siglo xIx el movimiento obrero logró formas de organización, además de una tradición de lucha importante. En las organizaciones sindicales y partidos obreros de vanguardia militaban numerosas mujeres. Algunas de ellas son figuras muy destacadas: Rosa Luxemburg, Alexandra Kollontay, Adelheid Popp en Europa y Emma Goldman en los Estados Unidos. La discusión sobre la problemática de la mujer fue muy importante en los núcleos vanguardistas, sobre todo en aquellos de los marxistas rusos. Sin embargo, no aparece claramente una ideología feminista o un análisis completo sobre la opresión de la mujer. Las dirigentes obreras en alguna medida colaboraron y defendieron la organización de las mujeres dentro de los partidos, a pesar del enorme trabajo de organización política en torno a la lucha del proletariado, a la que otorgaron prioridad. De cualquier forma, se puede señalar que todas compartían algo que quizás ya demostraron las trabajadoras en la Revolución Francesa: posiciones políticas que exigen una real democratización y participación de las bases en la conducción del movimiento obrero. La participación política de la mujer socialista aparece así con algunas características propias: su sentido democrático expresado en el deseo de igual participación de todos en el poder y su capacidad de sacrificio, que se expresa especialmente a nivel personal.

Las luchas del movimiento obrero a lo largo del siglo xIX culminaron con el triunfo de la revolución bolchevique. Las mujeres participaron en ella con entusiasmo. La situación de las mujeres en Rusia era particularmente retrasada comparada con el resto de Europa. Grandes masas de mujeres campesinas en las que el dominio del padre o del esposo era absoluto, determinaron que la primera tarea de la revolución soviética fuera organizar a estas mujeres, al mismo tiempo que se promulgaron un gran número de leyes para defender sus derechos. Derecho a la educación, derecho a trabajar, existencia de guarderías para sus hijos e intento de socializar las tareas domésticas. Al mismo tiempo, mujeres como Kollontay estaban especialmente preocupadas del problema de la libertad sexual y de la incidencia que esto tenía en la emancipación de las mujeres.

Los proyectos de la Revolución Rusa chocan con la realidad del momento. Es así como sectores importantes del Partido Comunista comienzan 
a plantearse que primero es necesario el cambio de la situación material, para luego proceder a las transformaciones culturales necesarias. Esto, sumado a las dificultades económicas entre los años veinte y comienzos de los treinta y a la llegada de Stalin al poder, produce un proceso de reversión de la mayoría de las leyes que tienen conexión con aspectos de la liberación de la mujer, tales como el aborto, el divorcio y el trabajo de la mujer en el hogar. Se vuelven a legitimar los valores de una familia tradicional, elevando la maternidad a la categoría de característica principal de la mujer. Pero se mantiene, a pesar de todo, el derecho de la mujer a trabajar en la producción, y por necesidades del sistema soviético la mujer es incorporada masivamente al trabajo. No deja por ello de ser responsable de las tareas domésticas y sufre así la explotación de la doble jornada.

La Revolución Rusa, así, a diferencia de la Revolución Francesa, legitimó la igualdad de hombres y mujeres. En un primer momento las leyes fueron amplias, incluyendo casi todas las reivindicaciones del movimiento feminista. Sin embargo, la práctica anuló muchas conquistas de las mujeres. Alguna, como el derecho a trabajar, sigue persistiendo; otras, sin embargo, como divorcio y aborto, fueron fuertemente restringidas. Se generó así una contradicción entre la ideología y la práctica. Pero a diferencia de la Revolución Francesa, en la que la burguesía sostiene tanto a nivel ideológico como práctico que el único lugar de la mujer es el hogar, la Revolución Rusa permitió la esperanza de que las contradicciones entre ideología y práctica se transformaran en algún momento en un movimiento reivindicativo de las mujeres. ${ }^{6}$

El siglo xix fue así testigo del surgimiento del feminismo proletario. Éste se caracteriza por la movilización y participación de las mujeres en las luchas sociales del movimiento obrero. A partir de la segunda mitad del siglo XIx y sobre todo del surgimiento del marxismo, el feminismo y el socialismo se relacionan. Las mujeres trabajadoras pretenden no sólo resolver sus propios problemas, sino colaborar en la transformación de la sociedad capitalista. Si bien son conscientes de su situación de inferioridad y desean iguales derechos a nivel de masas y a nivel de vanguardia, posponen sus propias reivindicaciones a las metas del movimiento general. Con gran espíritu de solidaridad y sacrificio, teniendo que enfrentar siempre los prejuicios y la opresión de sus propios compañeros de lucha, esa situación es posible que sea la causa de que no se desarrolle un pensa-

6. Para un análisis más completo sobre la situación de la mujer en los países socialistas, ver el artículo de Hilda Lass, en este mismo número de Papers. 
miento feminista autónomo dentro del movimiento socialista. No aparece así, en forma sistemática, una teoría sobre la opresión de la mujer y sobre la forma de relacionar la lucha feminista con la lucha del proletariado.

Esta ambivalencia se encuentra presente como es lógico en la revolución bolchevique, la única revolución socialista triunfante de este período, que logra introducir importantes reformas respecto a la situación de la mujer. A pesar de sus ambigüedades, vacilaciones y retrocesos, no es comparable con la traición de los hombres de la burguesía durante la Revolución Francesa. $\mathrm{Y}$ este avance se debe indudablemente al interés de los fundadores del socialismo por la problemática de la mujer.

La debilidad del feminismo proletario es su incapacidad de generar tanto en la teoría como en la práctica un movimiento feminista autónomo dentro del socialismo. Es decir, una forma de relacionar la lucha por la transformación de la sociedad capitalista con la lucha por la transformación de la sociedad patriarcal.

\section{El feminismo burgués}

Herencia de las mujeres elitistas, el feminismo burgués combina en el siglo XIX su desarrollo ideológico con movimientos reivindicativos. El más importante de ellos es el sufragismo, que si bien se desarrolló en casi todos los países europeos, principalmente en Inglaterra, fue especialmente importante en los Estados Unidos. El movimiento sufragista es mucho más conocido y ha sido más estudiado que los movimientos de las mujeres trabajadoras. Por ello, aunque ha sido mitificado e incluso distorsionado, ha permanecido más en la memoria histórica, identificándose, erróneamente, como el único movimiento importante de las mujeres en pro de la igualdad de derechos. Analizaremos a continuación el desarrollo del sufragismo norteamericano, pues nos parece ilustrativo del fenómeno que nos interesa.

En los Estados Unidos el movimiento de las mujeres por su igualdad se entrecruzó con una serie de movimientos sociales que se desarrollaron en el siglo xix. Ha sido siempre asociado con el desarrollo del movimiento abolicionista (contra la esclavitud), lo cual es cierto sólo en el caso del sufragismo. Sin embargo, no todo el movitniento de mujeres americano se reduce al de las sufragistas. Importantes movimientos de mujeres trabajadoras estuvieron relacionados con el nacimiento y el crecimiento del movimiento sindical. En algunos casos ambos movimientos coinciden. En otros, en cambio, actúan en forma paralela o con cierta oposición por parte de las sufragistas. 
Desde que se proclamó la irdependencia de los Estados Unidos, las mujeres comenzaron a reivindicar igualdad de derechos con los hombres, poniendo énfasis, especialmente, en la igualdad educacional. En 1830, cuando se forma el movimiento contra la esclavitud, en el que participaron muchas mujeres de clase media, los grupos que demandaban igualdad decidieron organizarse. La necesidad de esta organización surge tanto por los problemas que tenían dentro del movimiento abolicionista para poder expresarse como por la conciencia de que la libertad de los esclavos y la libertad de las mujeres eran dos temas estrechamente ligados. Esta fecha suele considerarse como el origen del movimiento sufragista. Sin embargo, las mujeres aún no planteaban el derecho a voto, sino que estaban preocupadas por varios síntomas más de la «superioridad masculina». Cuestionaban básicamente el derecho a la igualdad educacional, igualdad en la familia, igualdad religiosa (les preocupaba especialmente la posición institucional de la Iglesia contra la igualdad de las mujeres) e igualdad legal, especialmente en lo relativo a los derechos de propiedad.

El trabajo de organización de las mujeres en esta etapa culminó con la Convención de Séneca de 1848. Una convención para discutir sobre los derechos de la mujer que se convirtió en un hito histórico dentro del movimiento feminista. Las delegadas reunidas aprobaron una Declaración de Derechos de la Mujer (basada en la Declaración de la Independencia) que incluye todas las demandas feministas, entre ellas el derecho a voto.

La Convención de Séneca ha sido considerada como la iniciación del movimiento sufragista. Sin embargo, es incorrecto, ya que de hecho fue más tarde cuando las mujeres que allí participaron decidieron tomar el derecho a sufragio como su meta primordial de lucha. A pesar de esta salvedad, nos referiremos a ellas como las sufragistas.

Desde 1848 hasta la guerra civil en 1861, las sufragistas participaron en las campañas contra la esclavitud y desarrollaron convenciones para discutir los derechos de la mujer. Este período coincide con una etapa de amplia movilización de mujeres trabajadoras, principalmente de las fábricas textiles y los molinos. Si bien ambos movimientos se desarrollaron separadamente, coincidieron en el movimiento abolicionista.

El fin de la guerra civil trajo una gran desilusión al movimiento sufragista. Si bien se logró la abolición de la esclavitud, se decidió postergar el otorgamiento de iguales derechos a la mujer. En esto coincidieron los hombres abolicionistas con aquellos que se oponían a la abolición de la esclavitud. El principal argumento fue que cada cosa debía ser discutida a su turno y que ese momento era la «hora de los negros». Ya llegaría más adelante la «hora de las mujeres». Sintiéndose traicionadas, las mujeres decidieron organizarse en forma independiente. Sin embargo, no se logró 
un acuerdo sobre los objetivos ideológicos y tácticos prioritarios. Mientras un grupo de mujeres sostenía que se debía combatir por todos los derechos de la mujer, tanto el voto como la igualdad religiosa y familiar, otro sector consideraba que la demanda fundamental debía ser el derecho al voto, el que a su vez permitiría la consecución de todos los otros objetivos. Estas diferencias ideológicas se tradujeron en la existencia de dos organizaciones sufragistas separadas: la Asociación Nacional de Mujeres Sufragistas y la Asociación Americana de Mujeres Sufragistas. Durante veinte años lucharon por los derechos de la mujer en forma separada, hasta que en 1890 se fusionaron en una sola organización: la Asociación Nacional Americana de Mujeres Sufragistas, cuyo objetivo es el derecho a voto de la mujer. El sufragismo puro finalmente se impuso.

Treinta años más de lucha debieron transcurrir hasta que en 1920 se aceptó el derecho a voto de la mujer. Casi tres cuartos de siglo habían transcurrido desde que el movimiento sufragista nació. Durante estos años, las sufragistas habían participado en reuniones, convenciones, habían hecho campañas regionales y nacionales, habían trabajado en los parlamentos estatales y en el nacional, solicitando leyes que aprobaron el derecho a voto de la mujer (en los estados y en la Constitución). Cuando finalmente se logra la victoria, las sufragistas están extenuadas. El movimiento se desintegra sin plantearse nuevas metas.

La relación de las sufragistas con las organizaciones de las mujeres trabajadoras cambió en el transcurso del tiempo. Antes de la guerra civil existió cierto apoyo a los problemas y luchas de las negras y las trabajadoras, no siempre en forma unánime. En la Convención de Séneca, por ejemplo, en la que todas las resoluciones expresaban claramente principios por todos compartidos, una de ellas se hace parcial: «Aquellos que crean que las mujeres de las clases trabajadoras están oprimidas, deberían hacer todo lo posible por elevarles el salario, empezando por sus propias sirvientas domésticas.» ${ }^{7}$ (En verdad en esos momentos la opresión de las mujeres de la clase trabajadora distaba mucho de ser materia de creencia: era una realidad apabuillante.)

A partir del fin de la guerra civil, las sufragistas comenzaron a considerarse más un grupo de segunda clase de la clase media blanca que un grupo con similitud con los oprimidos del país, ya sean éstos negros o trabajadores. Su punto de referencia es más lograr la igualdad con los hombres de clase media que combatir con los movimientos de los otros grupos. Si bien la Asociación Nacional de Mujeres Sufragistas (no restringidas al su-

7. Sacks, op. cit. (1976), p. 32. 
fragio) muestra un cierto apoyo por las luchas sindicales de las mujeres y los trabajadores (dentro de un marco paternalista), su fusión con la Asociación Americana termina con esta tendencia. La nueva organización unitaria está marcada por un sentimiento hostil tanto a los sindicatos como incluso a las mujeres negras (esto último por la asociación con las mujeres blancas del Sur).

Así, cuando los trabajadores del metal son fuertemente reprimidos por las tropas federales durante una huelga, la líder sufragista, Lucy Stone, «quería saber por qué éstos no se dedicaban a los negocios si no les gustaba su trabajo», y Susan Anthony, la dirigente sufragista más importante, señalaba que «las sufragistas no debían intervenir en contra de la ley que prohibía a los negros (incluso las mujeres) el usar asientos en el tren». ${ }^{8}$ $\mathrm{Al}$ mismo tiempo los argumentos a favor del sufragio de las mujeres es el de que la mujer educada tiene mucho más en común con los hombres de clase media americanos que con los trabajadores, negros $e$ inmigrantes ignorantes y pobres. Que es el voto de éstos lo que pone en peligro al país y que frente a ellos los hombres deberían considerar a las mujeres sus naturales aliadas contra los trabajadores.

El sufragismo, a pesar de la oposición sistemática de los hombres de la clase media, no rompe entonces con su posición de clase, sino que la acentúa en el transcurso de la lucha.

\section{Cbile: mujer y contrarrevolución}

El caso chileno es indudablemente un ejemplo muy interesante sobre la división de la mujer en clases sociales, por dos razones: es un ejemplo históricamente cercano y porque refleja nítidamente la reacción de clase de la mujer burguesa, frente a la posibilidad de la transformación revolucionaria de la sociedad capitalista.

Como en la mayoría de los países periféricos, el feminismo, sobre todo lo que se ha llamado feminismo burgués, tuvo poco desarrollo en Chile. La mujer burguesa logró incorporarse a los niveles educativos a fines del siglo xIx, incluida la universidad. A lo largo del siglo xx una proporción importante de mujeres provenientes de la clase media y alta se incorporaron a trabajos profesionales y de servicios. Colaboró en esta posibilidad el hecho de que la mayoría de estas mujeres contaban con servicio doméstico. Si bien no hubo un movimiento sufragista, un pequeño grupo de mujeres logró presionar a los grupos políticos y obtuvo el derecho a

8. Ibid., p. 39. 
voto en 1949. Estas mismas mujeres intentaron organizar un Partido de la Mujer, que desapareció poco tiempo después de ser creado.

La mujer trabajadora participó en ese período en la creación de los sindicatos y posteriormente en las luchas sindicales. La relativa desorganización de la familia de la clase trabajadora le proporcionó un rol muy importante en ella. Predominio de uniones libres, más la desintegración familiar, convirtieron a la mujer chilena en el jefe de familia en muchos casos. Su incorporación al trabajo, sin embargo, no se produjo en el sector industrial (dado el escaso desarrollo industrial chileno), sino que fue utilizada en los trabajos domésticos de los hogares de la mujer de clase media y de la burguesía.

La participación política de la mujer a partir de la conquista de su derecho a voto no presentó características espectaculares. Se incorporó masivamente a las elecciones, reflejando, sí, un mayor índice de apatía que el electorado masculino. La orientación de su voto fue más conservadora que la de los hombres, sobre todo a partir del crecimiento de la democracia cristiana, en 1964, a la que se incorporó mayoritariamente. En las elecciones presidenciales, a partir de 1958, la izquierda chilena fue derrotada electoralmente precisamente por los votos de las mujeres. Es así como, en 1970, la Unidad Popular, a pesar de su victoria, obtuvo una cifra considerablemente mayor de votos masculinos que femeninos. La democracia cristiana, que durante el gobierno de Frei (1964-1970) había hecho un esfuerzo gigantesco de organización de la mujer de la clase trabajadora en centros de madres (organización de barrio, especialmente importante en las poblaciones marginales) obtuvo los frutos de su política en un fuerte apoyo del electorado femenino.

Fue durante el gobierno de la Unidad Popular cuando la participación de las mujeres de la burguesía y clase media adquirió una importancia fundamental. Merced a la organización de la derecha, se convirtió en un movimiento de masas cuya tarea primordial fue lograr el derrocamiento del gobierno popular. La derecha chilena, que luego de su fracaso electoral en 1970 se encontraba desorganizada y sin un movimiento de masas que la sustentase, dedicó sus energías a reorganizarse. Para ello, en alianza con los Estados Unidos, utilizó todos sus recursos para lograr ell apoyo de distintos grupos sociales. Sus intentos de dividir a la clase trabajadora fracasaron. En cambio encontró en las mujeres organizadas alrededor de la mujer burguesa la mayor potencialidad de acción en su estrategia contrarrevolucionaria. Es así como las mujeres de la burguesía participan en el movimiento contrarrevolucionario: golpeando cacerolas por las noches, manifestándose por las calles, reunićndose frente al Congreso chileno para pedir la dimisión de Allende. 
Para lograr la incorporación masiva de la mujer a la política, la derecha debió romper alguno de los elementos tradicionales de la ideología del rol de la mujer. Así comenzó una campaña a través de los medios de comunicación de masas para hacer notar a las mujeres que su rol no estaba sólo en el hogar, sino que también estaba en las calles luchando por oponerse a la implantación del comunistno en Chile.

La situación social de la mayoría de la mujer chilena fue una gran ayuda para la organización y desarrollo de este movimiento de mujeres contra la Unidad Popular. El porcentaje de mujeres que participaba en la producción era muy bajo. La gran mayoría de las mujeres permanecía en su hogar realizando sólo tareas domésticas. Esa situación posibilitaba que los medios de comunicación de masas, en especial la radio, tuvietan una importancia fundamental en lo que respecta a la mujer. La derecha chilena, que controlaba la mayoría de estos medios de comunicación de masas, los puso todos al servicio de la misma causa: imposibilitar la instauración del socialismo en Chile. Ahora bien, para lograr esta movilización de masas, la burguesía debió romper con alguno de los conceptos tradicionales sobre la feminidad. Pero sólo con algunos de ellos. Si bien se dice que es igualmente importante que la mujer participe de la vida familiar como de la vida política, se justifica la participación política en términos de la defensa de valores permanentes, tales como la familia. A pesar de ello, se inició una ofensiva ideológica para hacer que las mujeres rompieran su pasividad tradicional y se incorporaran masivamente a la «santa cruzada» contra el gobierno popular.

A nivel de masas se logró movilizar a todos los sectores de la mujer de la burguesía y a alguno de los sectores de las mujeres trabajadoras, agrupadas en los centros de madres fundados durante la época demócrata cristiana. Estas mujeres participaron en forma mayoritaria en las movilizaciones en la calle, a las cuales llamó la derecha. En la última fase de su oposición al gobierno de Allende, en muchas ocasiones, se convocó sólo a manifestaciones de mujeres.

Es notable, sin embargo, el hecho de que, a pesar de la falta de una política para la mujer por parte de la Unidad Popular y de la situación de crisis en el abastecimiento que se había logrado producir y que afectaba fundamentalmente a las mujeres de los trabajadores, la Unidad Popular logró un importante avance en las elecciones de 1973. Es decir, en esta situación, de un claro y fuerte enfrentamiento entre las clases sociales, las mujeres de los trabajadores optaron por los partidos que representaban a la clase trabajadora y al gobierno de la Unidad Popular. Durante los tres años de enfrentamiento surgió un fuerte sentido de solidaridad de la mujer de la clase trabajadora con el gobierno popular, sentido que no era pro- 
ducto de la política específica de la Unidad Popular hacia las mujeres. Se debe señalar que la política para la mujer de los partidos de la izquierda introdujo pocos factores que rompieran la ideología tradicional de la familia y de la situación de la mujer en ella. Prácticamente no hubo planteamientos feministas en ninguna de las organizaciones femeninas del gobierno popular, que se desarrollaron durante esos tres años.

Simultáneamente con esta lucha femenina de masas, la derecha emprendió una lucha vanguardista. Mujeres de la burguesía se encargaron sistemáticamente de hacer una campaña psicológica en torno a los oficiales del ejército. Para ello se apeló a todos los valores machistas tradicionales. Las mujeres realizaron manifestaciones frente a la Escuela Militar, lanzaron granos de maíz en algunos cuarteles como símbolo de falta de hombría por parte de los oficiales y organizaron movilizaciones contra los oficiales constitucionalistas. Prat, general en jefe del ejército, cuya renuncia abrió el camino a Pinochet posibilitando así el golpe, debió renunciar ante una manifestación de mujeres de oficiales del ejército. Dentro de esta línea vanguardista actuó un grupo llamado Poder Femenino, grupo que incluyó en su plataforma reivindicaciones feministas. Paula, revista que fue el portavoz durante los últimos años de las inquietudes por la igualdad de la mujer, emprendió una campaña sistemática contra el gobierno de la Unidad Popular y contra el estableciminto del socialismo en Chile.

En las movilizaciones tanto de masas como de vanguardia, las mujeres de la burguesía (y la burguesía en general) tuvieron especial cuidado de no aparecer como líderes del movimiento. Por el contrario, se trató de mostrar que la oposición al gobierno popular reflejaba todos los sectores de la población. Es así como por primera vez en su historia las mujeres de la burguesía chilena se solidarizaron con una huelga obrera: la de los mineros de la mina El Teniente. Esta huelga por reivindicaciones económicas abarcó inicialmente a todos los trabajadores, pero se redujo a una minoría de ellos cuando la derecha comenzó a usarla políticamente. Sin embargo, los partidos de derecha y la democracia cristiana desplegaron todos sus recursos en apoyo de esta minoría. Mujeres de la clase alta recolectaron fondos en apoyo y organizaron una «olla común» simbólica.

El movimiento de mujeres fue usado para demostrar que la división en clases, que tanto señalaba la izquierda, en realidad no existía. Las mujeres no permiten que se las divida por clases, constituyen todas un grupo con intereses comunes. Ellas, que nunca han sido políticas, están demostrando con su participación que de lo que se trata aquí es de un enfrentamiento entre los patriotas que tratan de salvar el país y los que tratan de destruirlo. Los medios de comunicación de la derecha insistieron una y otra 
vez en esta idea. En la movilización se intentó poner en primera fila a las pocas mujeres trabajadoras que la apoyaban.

Esta definición de la situación anticipó lo que sería la ideología del futuro gobierno militar: el corporativismo fascista.

Una vez triunfante el golpe militar y establecida la junta fascista del general Pinochet, éste señaló su profundo agradecimiento a la participación de las mujeres y su intención de incorporarlas a tareas políticas de gobierno. Lo que efectivamente hizo, pero sólo en lo que respecta a aquellas vanguardias de mujeres de la burguesía claramente comprometidas con una ideología y una práctica fascista. Se nombraron mujeres ministros, mujeres embajadoras que no habían existido antes en ningún otro gobierno. Sin embargo, estas dirigentes, de las cuales la propia esposa de Pinochet es el mejor ejemplo, reclamaron al resto de las mujeres la vuelta a casa y la asunción de sus roles tradicionales, que momentáneamente habían abandonado para participar en la lucha patriótica contra el socialismo. Las mujeres de la clase trabajadora fueron fuertemente golpeadas por la política económica y por la represión que sufite el país en general. Las mujeres de la burguesía tienen, en carabio, una significativa e importante participación en el gobierno militar.

Este modelo de movilización de las mujeres contra los movimientos populares no es nuevo en los países del impropiamente llamado Tercer Mundo, en especial América Latina. Sin embargo, en el caso chileno aporta algunos elementos específicos novedosos. En primer lugar, la movilización de las mujeres no se hizo exclusivamente en términos tradicionales. En el caso brasileño, por ejemplo, se había recurrido a la movilización a través de la defensa de la religión. En Chile, en cambio, se permitió la incorporación al movimiento de nuevos elementos ideológicos, especialmente los relativos a la necesidad de participación política de las mujeres. Luego de producido el golpe, en efecto, se incorporaron algunas mujeres a puestos de poder. Son sólo algunas mujeres representantes de una determinada clase social. En segundo lugar, el fascismo chileno acentuó especialmente la idea de que todas las mujeres deben estar unidas, pues forman un grupo social homogéneo. Este argumento es usado por las mujeres de la burguesía para señalar a las mujeres de la clase trabajadora que ellas no deben identificarse con sus compañeros, sino con lo que ellas representan. Organizaciones paternalistas, como los centros de madres, contribuyen a fortalecer esta idea de unidad entre todas las mujeres. En la práctica, una vez que Ia derecha consigue sus propósitos, esta idea de unidad desaparece. Las mujeres de la burguesía vuelven a su posición económica privilegiada y logran algunas conquistas políticas. La mujer de la clase trabajadora sufre el peso de la represión y la escasez económica. La solidaridad de la mujer 
burguesa con los trabajadores, que tanto pregonó durante la huelga de mineros, por ejemplo, se acaba. Todo vuelve a su sitio.

\section{Conclusiones}

La historia demuestra que la mujer no ha aceptado en forma pasiva su situación de opresión. En muchas ocasiones se ha rebelado, aunque esta rebelión pueda ser limitada en sus objetivos o restringida en su base social.

EI feminismo aparece como la forma ideológica y orgánica de canalizar el descontento de las mujeres. Ha expresado los problemas de mujeres socialmente diferentes, en diversas sociedades y en diferentes situaciones históricas. Es así como no se puede hablar de un feminismo único; han existido, por lo menos, dos tipos de feminismo y ambos han sufrido transformaciones y modificaciones en el curso de su desarrollo y crecimiento. Son los que hemos denominado feminismo burgués y feminismo proletario.

$\mathrm{El}$ análisis de las expresiones históricas de ambos ha mostrado que entre ellos hay diferencias sustanciales, aunque ambos se originen en el hecho de que todas las mujeres sufren algún tipo de discriminación. Las mujeres de la burguesía y las mujeres de la clase trabajadora han mostrado tener reivindicaciones específicas diferentes, lo que las ha llevado a formas de organización y lucha paralelas, cuando no contrapuestas. La ideología feminista que se ha desarrollado a partir de esta práctica ha sido, por lo tanto, necesariamente distinta. Mientras que para la mujer burguesa el problema principal radicaba en lograr la igualdad con los derechos de los hombres de su clase, el primer problema de la mujer trabajadora era superar la situación de explotación económica que sufría y que la afectaba en la misma forma que a sus compañeros. Las mujeres, en su conjunto, entonces, tienen tantos intereses comunes como intereses opuestos.

Sus intereses comunes provienen de su situación de inferioridad con respecto al hombre de su propia clase. Es decir, simplemente por el hecho de ser mujer sufre una forma de opresión. Sus intereses contradictorios provienen de que es miembro de una clase social determinada. Si bien no es directamente burguesa (en la medida en que no es propietaria de los medios de producción) o puede no ser trabajadora, si no participa en la producción (aunque hay una mayor proporción de mujeres trabajadoras que burguesas), es la mujer de un burgués o de un proletario. En el primer caso goza de los privilegios de ser parte de la clase dominante; en el segundo, sufre las consecuencias de la explotación a la que es sometido su compañero. Si bien no quiere ser oprimida por el simple hecho de ser mujer, si es trabajadora querrá transformar radicalmente la sociedad capi- 
talista. Si es parte de la burguesía, no querrá perder sus privilegios, aunque quien los obtenga sea su hombre.

Los datos analizados muestian como estos intereses contradictorios entre las mujeres aparecen nítidamente en las situaciones de enfrentamiento social, haciendo que las burguesas se enfrenten a la clase trabajadora en su conjunto (incluyendo a las propias mujeres). Cuando este enfrentamicnto no es tan radical, dichos intereses se expresan en la existencia de dos movimientos paralelos y distintos: las reivindicaciones de unas y otras, aunque tienen algunas coincidencias, expresan también diferencias manifiestas.

Sin embargo, hay dos hechos que parece importante destacar. En primer lugar, las feministas burguesas son mucho más liberales que sus compañeros de clase. En situaciones específicas establecen alianzas y asumen algunas de las causas por las que luchan los trabajadores, en la medida que intentan incorporar reivindicaciones de las trabajadoras en una plataforma común de lucha de todas las mujeres. Pero esto sucede sin ceder la hegemonía del movimiento feminista. (Ejemplo de ello son las corrientes más radicales del sufragismo.) Es decir, sin subordinarse a las reivindicaciones de las trabajadoras.

En segundo lugar, la solidaridad constante que la mujer trabajadora ha mostrado con las luchas de su clase no ha tenido la misma contrapartida por parte del hombre proletario. El marxismo ha mostrado a nivel teórico simpatía por la problemática de la mujer (lo que no ha existido en la ideología de la burguesía). Su práctica y la del movimiento obrero, en cambio, han sido muy distintas.

La práctica feminista que desarrolle la mujer trabajadora debe tomar en cuenta ambos hechos. A largo plazo tendrá necesariamente diferencias importantes con los intereses de la mujer de la burguesía aunque puedan haber coincidencias. Tampoco puede esperar que el fin de su opresión se la otorguen sus compañeros proletarios. No puede, por lo tanto, subordinarse a unas o a los otros. Debe tomar: en sus propias manos la construcción de su liberación, definiendo correctamente sus intereses, sus aliados y sus enemigos. 